ARTICLE HISTORY: Received: January 6, 2021 Accepted: February 24, 2021 Published: March 3, 2021

УДК 659.1 МАРКЕТИНГОВЫЕ МАНИПУЛЯЦИИ И АДДИКТИВНЫЕ ТЕХНОЛОГИИ -
ВИРУС СОВРЕМЕННОСТИ

Киселева А.Э.

Студентка 3 курса напр. «Менеджмент»,

ПИУ РАНХиГС им. П.А. Столыпина,

2. Саратов, Российская Федераиия.

\title{
MARKETING MANIPULATIONS AND ADDICTIVE TECHNOLOGIES - THE VIRUS OF THE CONTEMPORARY
}

A.E. Kiseleva,

3rd year student, field of study - «Management», Povolzhsky Institute of Management named after P.A. Stolypin, branch of RANEPA,

Saratov, Russian Federation.

Аннотация. На сегодняшний день сложно встретить человека, не являющегося пользователем социальных сетей или компьютерных игр. Многие даже не догадываются о пагубном влиянии технологий, которые скрываются за красочными дизайнами приложений. В данной работе подробно раскрывается проблема воздействия аддиктивных технологий на здоровье человека, а также проводится социальное исследование, определяющее уровень осведомленности населения об изучаемых в рамках данной темы технологиях.

Abstract. Today it is difficult to meet a person who is not a user of social networks or computer games. Many people are not even aware of the pernicious influence of technology behind colorful app designs. This work reveals in detail the problem of the impact of addictive technologies on human health, and also conducts a social study that determines the level of awareness of the population about the technologies studied within this topic.

Ключевые слова: зависимость от приложений, аддиктивные технологии, манипулирование, внедрение технологий, социальное исследование, интернет-зависимость, внедрение технологий в разработку приложений.

Keywords: application addiction, addictive technologies, manipulation, technology implementation, social research, Internet addiction, technology implementation in application development.

На сегодняшний день более 4,6 миллиарда людей пользуются интернетом, а аудитория социальных сетей перевалила за отметку в 3,8 миллиарда (рисунок 1). Почти $60 \%$ мирового населения уже онлайн, и есть все основания полагать, что уже к середине года половина всех людей на планете будут пользоваться соцсетями. Несомненно, нынешние технологии работают в интересах общества, интернет дает нам многое, но и забирает немалое. Действительно ли технологии нацелены на общество, а не против него?
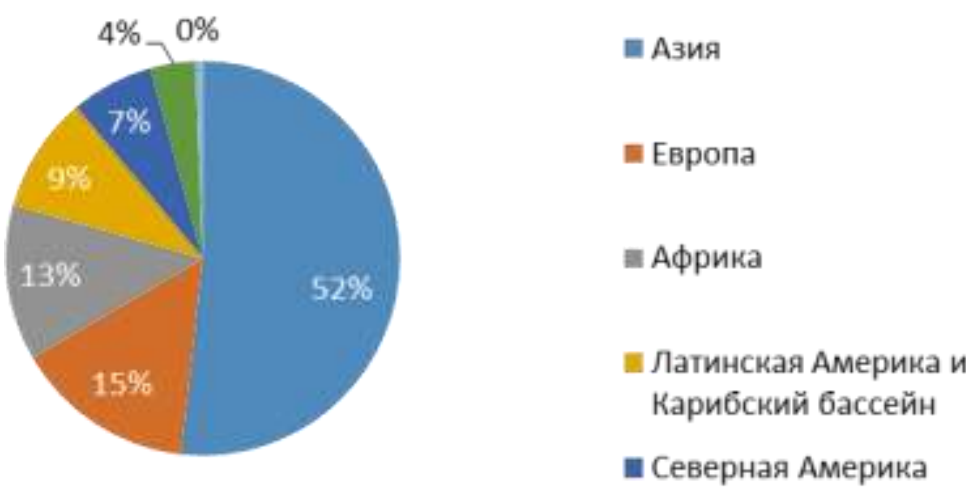

Рисунок 1. Прочентное соотночение интернет-населения. 
Согласно статистике, среднестатистический пользователь тратит в сети 6 часов 43 минуты ежедневно, на каждую секунду дня приходится 6,59 млрд ГБ интернет-трафика. В чем секрет столь долгого пребывания человека в сети? Верно ли полагать, что дело только в общении и получении информации?

За играми и цифровыми сообществами, которые пользуются спросом у мирового населения, стоят психологи и другие эксперты в области наук о поведении, которые создают «цепляющие» аудиторию продукты. 150 тысяч новых приложений регистрируют в App Store и Google Play каждый месяц. Привлечь внимание пользователей и добиться коммерческого успеха помогает продуманный дизайн мобильных приложений. Так, согласно исследованию McKinsey, в компаниях с хорошим дизайном рост выручки больше на треть. На сегодняшний день специалисты по психиатрии пользуются активным спросом у крупнейших технологический компаний. Профессионалы помогают внедрять технологии привыкания (аддикции) в дизайны приложений данных компаний. Научные исследователи занимаются изучением влияния компьютерной техники на поведение человека и его образ мысли. Рассматриваемая техника, также известная как «аддиктивный дизайн», уже заимела популярность в тысячах играх и приложениях, ее активно используют такие компании, как Facebook, Twitter, Snapchat, Amazon, Apple и Microsoft для того, чтобы особые модели поведения формировались у пользователей еще с самого раннего возраста [1].

Основоположником исследования данного явления является ученый-бихевиорист из Стэнфордского университета Би Джей Фогг. Исследователи по бихевиоризму испытвают особый интерес в изучении того, какое влияние на поведение людей может оказывать цифровой интерфейс - коробка, в которой сегодня большинство людей проводят большую часть своего времени. Эта относительно молодая дисциплина приобрела название «бихевиоральный дизайн». Фогг является основателем целой области науки, которая базируется на исследованиях, показывающих, как при использовании небольшого количества методов, готовый продукт может оказывать манипуляционное воздействие на поведение человека. В нынешнее время его исследования это готовая инструкция для компаний, разрабатывающих продукты, цель которых как можно дольше удерживать пользователей «в сети» [3].

Работа аддиктивных технологий или аддиктивного дизайна крайне проста: чтобы изменить модели поведения, человеку нужны мотивация, возможность и триггеры. В случае с социальными сетями мотивацией служит жажда людей к общению или страх отторжения обществом. Что касается компьютерных игр, то тут мотивирует желание получить какие-либо навыки или достижения. Простота использования продукта необходимое условие для реализации такого дизайна. Важно добавить и триггеры, - стимулы, которые побуждают людей возвращаться снова и снова. К примеру, в социальных сетях существуют такие видеозаписи, от которых невозможно оторваться или виртуальные бонусы за большую часть времени, проведенную в приложении, также секретные сундуки с сокровищами, которые игроки получают при достижении определенного уровня в игре. Все это можно назвать триггерами, элементами аддиктивного дизайна.

Большинство компании, которые активно занимаются разработкой социальных сетей, строят свои продукты вокруг такого дизайна. Иногда после входа в Twitter оповещения приходят пользователю не сразу, а через несколько секунд. Twitter делает это умышленно - компания разработала алгоритм, который заставляет пользователей дольше оставаться на сайте. У компании Facebook есть подобное расписание, согласно которому сайт приберегает для пользователя оповещения, а потом выдает их в нужный момент. Это расписание составляется так, чтобы стимулировать человека снова заходить на сайт. iPhone и Apple в данном случае выступают проводниками, благодаря которым пользователи получают доступ к социальным сетям и играм [1].

В числе этих пользователей присутствуют также дети и подростки, более уязвимая часть общества. Аддиктивные технологии оказывают непосредственное влияние на детей своими манипуляциями и порождают изоляцию, которая заставляет молодое поколение отдалиться от основных реалий повседневной жизни: от учебы в школе, от взаимодействия с семьей, от дружеских отношений. Дети и подростки крайне восприимчивы относительно социальных взаимодействий, особо чувствительны к ощущениям принятия или отрешенности в обществе. Социальные сети, сети интернет создаются с направленностью на то, чтобы наживаться на этих возрастных особенностях. Здесь также важно сказать о последствиях воздействия аддиктивных технологий на неокрепший молодой организм [2]. Так как это все-таки прямое воздействие на психику человека, то в данном случае возможны появления различного рода психических отклонений и заболеваний, в т.ч. неустойчивость нервной системы, постоянная агрессия, неконтролируемый гнев, а в крайних случаях и суицид.

Опасность данных манипуляций известна не всем людям, как и сам факт наличия этих манипуляций, но есть все-таки небольшое число пользователей, которые имеют представления об аддиктивных технологиях, и благополучно игнорируя, продолжают пользование. Этот феномен связан с сочетанием нескольких вещей. Существует сама природа дизайна этих приложений. Это эффект игрового автомата: довольно старый способ, который переделан на новый лад, где пользователи сети могу найти что-то действительно смешное, образовательное или информативное, не представляя того, как этот момент дофамина или восторга ударит их.

В рамках заявленной темы мною был поведен опрос среди представителей школьного возраста, молодых людей и взрослого поколения. В опросе приняли участие 110 человек из разных областей России (Рисунок 2). 
Цель опроса заключалась в определении осведомленности населения в использовании компаниями маркетинговых манипуляций и аддиктивных технологий.

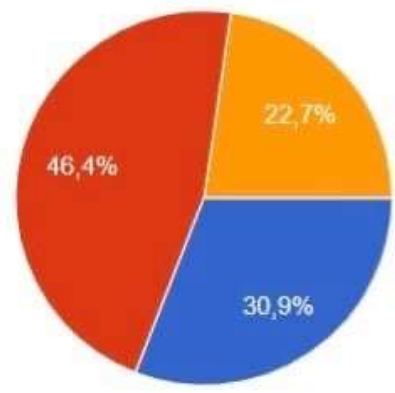

меньше 18

$18-25$

больше 25

Рисунок 2. Возрастное соотношение опрошенных.

Респондентам был задан вопрос «Как часто Вы пользуетесь интернетом?». Большая часть опрошенных проголосовала за варианты «больше шести раз в день» и «непрерывное использование». Исходя из этого, можно предположить, что столь частое посещение сети интернет может быть обусловлено наличием зависимости от тех или иных приложений. Вторая часть респондентов относится к посещению интернета относительно безынтересно (Рисунок 3).

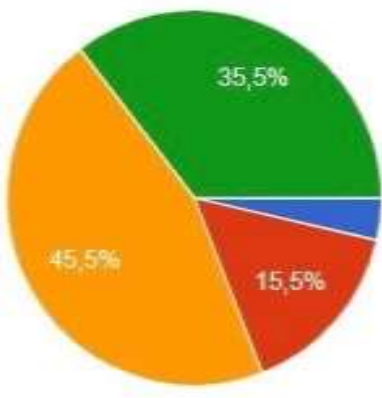

1-2 раза в день

3-6 раз в день

больше 6 раз в день

нелрерывное пользование

Рисунок 3. Частота использования интернет порталов.

На вопрос «Какими видами приложений Вы пользуетесь чаще всего?», 93 человека ответили «социальные сети», 3 человека выбрали вариант «игры», 5 человек ответили «новостные порталы» и 9 респондентов отметили вариант «другое». Процентное соотношение ответов представлено на рисунке 4. Опираясь на ответы опрошенных, можно сказать, что большая часть интернет населения нацелена на использование социальных сетей, так как на подобных платформах сосредоточены не положительные моменты в виде постоянно поступающей информации, но и наибольшее воздействие на сознание потребителей при помощи триггеров и аддиктивного дизайна.

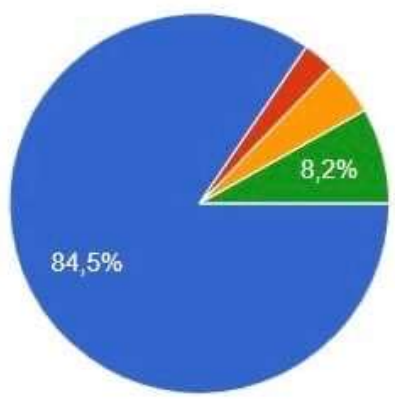

Социальные сети

Игры

Новостные порталы

Дpyroe

Рисунок 4. Приоритет используемых приложений.

Также, в ходе опроса выяснилось, что значительная часть респондентов не имеют ни малейшего представления об использовании аддиктивных технологий в работе приложений и об опасности, которая 
представляет собой пагубное влияние данных технологий на психику человека. На вопрос «Знаете ли Вы, что такое аддикция?» большинство опрошенных затруднились ответить (59 человек) или ответили неверно (3 человека), но оставшаяся часть выбрали верный вариант ответа (Рисунок 5). На вопрос «Знаете ли Вы, что такое аддиктивный дизайн?», большая часть респондентов также затруднились с ответом (71 человек) или же ответили неверно (11 человек), но 28 человек из 110 опрошенных все же смогли ответить верно (Рисунок 6).

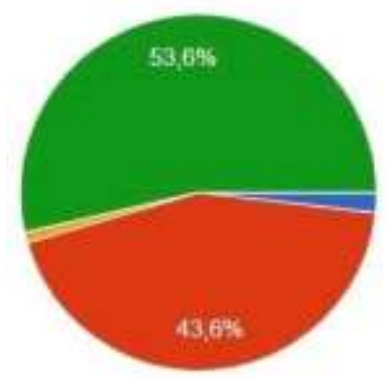

Tехнопогия поспойного нарацинания и синтеза обьектов

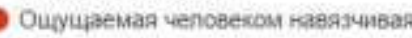
nотреб̆ность в anределённй деятельности

Fny6okse всесторонимe nosнarste широкая осведомпеность

Затрудняюco orventr

Рисунок 5. Прочентное соотночение осведомленности респондентов в понятии «аддикция».

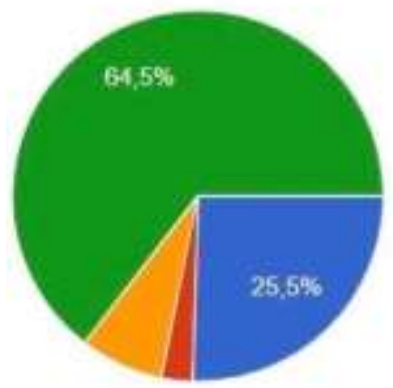

Технопогии привыкания в дизайне припокений

Вид современного искусства

Наука адаптации интерьеров под korkpensoro чenoseka

Затруднгось ответить

Рисунок 6. Процентное соотношение осведомленности респондентов в понятии «аддиктивный дизайн».

Опираясь на данные исследования, важно сказать, что население попросту не знает всей проблемы присутствия и влияния аддиктивных технологий на психику и поведение, и это еще раз доказывает факт развития компаниями, а точнее манипуляциями, которые они активно используют в своей практике, зависимостей, не согласованных с волей человека. Если в дальнейшем люди не будут знать всей опасности данного явления, то вскоре интернет поглотит все человеческое на земле. Чтобы этого не произошло важно проводить ряд мероприятий на уровне школ, институтов, рабочих организаций, направленных на осведомление поколений в данном вопросе.

\section{Список литературы:}

1. Электронный ресурс// URL: https://www.kramola.info/vesti/protivostojanie/kak-sozdayut-dizayny-servisov-iustroystv-vyzyvayushchih-zavisimost (Дата обращения: 12.02.2021).

2. Бувшик Софи. / How to Stop Doomscrolling News and Social Media/ Scientific American/ Электронный pecypc// URL: https://www.scientificamerican.com/article/how-to-stop-doomscrolling-news-and-social-media/ (Дата обращения: 13.02 .2021$)$.

3. Зеньков А. / Как наука делает нас зависимыми от приложений/ The Economist. / Электронный ресурс// URL: https://rb.ru/longread/addictive-apps/ (Дата обращения: 13.02.2021).

\section{References}

1. Electronic resource // URL: https://www.kramola.info/vesti/protivostojanie/kak-sozdayut-dizayny-servisov-iustroystv-vyzyvayushchih-zavisimost (Date of access: 12.02.2021).

2. Buvshik Sophie. / How to Stop Doomscrolling News and Social Media / Scientific American / Electronic resource // URL: https://www.scientificamerican.com/article/how-to-stop-doomscrolling-news-and-social-media/ (Date of access : 13.02.2021).

3. Zenkov A. / How Science Makes Us Dependent on Applications / The Economist. / Electronic resource // URL: https://rb.ru/longread/addictive-apps/ (Date of access: 13.02.2021). 